\title{
Automated Method Research on College Student Scholarship Evaluation
}

\author{
Qiao Zhang* \\ School of Electrical and Electronic Engineering \\ Wuhan Polytechnic University \\ Wuhan, China
}

\author{
Zhen Kang \\ School of Mathematics \& Computer Science \\ Wuhan Polytechnic University \\ Wuhan, China
}

\author{
Junlei Yang \\ School of Electrical and Electronic Engineering \\ Wuhan Polytechnic University \\ Wuhan, China
}

\begin{abstract}
The scholarship assessment is one of the regular work of the counselors, which is related to the vital interests of the most students. The traditional method is that the counselors manually add points and re-rank the students who meet the conditions according to the ranking in the student education system. This kind of work is time-consuming and error-prone. This paper presented an automated method to evaluate the college student scholarships, which uses computer programming technology to add and sort the students' scores. A lot of experiments had implemented to test the accuracy of the algorithm and the experimental results proved that it could improve the work efficiency and the accuracy and greatly reduce the work pressure of counselors. Most of the experimental data come from the students in our college, whose performance data come from the educational management system, and the winning information come from the student work management system. In summary, the work has important theoretical and practical significance for the daily work of the counselors and the administrative departments.
\end{abstract}

Keywords—school-level scholarship; scholarship assessment; automated method; student management

\section{INTRODUCTION}

Scholarship assessment is a tedious and procedural work in the management of college students. Through a survey of some counselors in our school, it is found that the scholarship assessment work is very important, the workload is large and complex, but there is no specific unified management software [1]. In October each year, the school will issue a scholarship assessment notice. The colleges will summarize the student's grades and awards, and manually create a temporary small database in the computer to calculate and summarize the scholarship information. This not only makes the work inefficient, error-prone, and the format is not uniform and irregular, resulting in great waste of manpower, material and financial [2-5]. This paper has realized the automation of the scholarship assessment process firstly, and then the automation of the whole school scholarship management project will be achieved through network construction. Therefore, the information management of college scholarship projects can be

Fund Project: Funded by school research project (No.2019S10) standardize, institutionalize, and project scholarship assessments, improve management levels, and reduce management costs.

\section{SignificAnCE OF AutOMATEd Method RESEARCH ON} SCHOLARSHIP EVALUATION IN COLLEGES AND UNIVERSITIES

\section{A. The Significance of the Establishment of Scholarships in Colleges and Universities}

In order to improve the quality of students, promote the construction of study style, mobilize the enthusiasm of the students to be determined to become a talent and to strive up, and then set up different levels of scholarships. The scholarship assessment is also the most extensive, in-depth and most important examination and encouragement for students [3]. Every student hopes to get a certain scholarship through hard work, because it can not only provide some financial assistance to the students, but also is the best proof of their efforts and achievements [4].

The scholarship assessment requires clear and measurable conditions for various scholarships, and the provisions of the scholarship conditions should be moderate. Only by clarifying the conditions of scholarships, the student can clearly understand the requirements and conditions of various scholarships, it is beneficial to guide students to establish their own scholarship goals, clarify the direction and extent of efforts, improve the expectations of students' awards, and mobilize the enthusiasm of most students, to enhance the incentive effect.

\section{B. The significance of the Scholarship Assessment Automation Method}

Today, with the rapid development of the internet, computer technology has been fully applied to various fields, especially in data management and use. As the number of students increases, the pressure on student management increases. The scholarship assessment is a very important part of the student management process and repeat every year. In addition, the scholarship assessment procedure is relatively 
fixed, with strict conditional restrictions and proportional control, and is simple to implementation. On the one hand, it is must to refer to the academic performance of each subject of the students. On the other hand, it is necessary to combine the specific performance and actual situation of each student, including the moral education, sports and some outstanding performances of the students, and give a certain extra score. The scope involved is very wide, and the data that needs to be recorded and processed is also very large, so it is not easy to assess the level of scholarship recipients according to different situations. If you use the traditional scholarship manual assessment method, it not only increases the workload of the counselor, but more importantly, it will inevitably lead to omissions or errors in the implementation, and it will inevitably lead to repeated labor and take a lot of time [5]. Therefore, the automated implementation of scholarship assessment is very necessary.

Firstly, it provides a theoretical and practical basis for the full realization of the automatic evaluation system for college scholarships. Since the current scholarship evaluation is still based on manual document operation [6], in order to fully realize the automation of scholarship management, it is necessary to have a practical process and gradually achieve the purpose of mature application.

Secondly, it can promote the standardized management of the scholarship assessment process. The scholarship assessment automation can update and monitor the data in real time, and it can also effectively save the working hours of the lower and upper levels of the scholarship management [7].

Thirdly, the results openness of the scholarship assessment has been strengthened. The implementation of the scholarship assessment automation avoids many subjective factors and makes the scholarship management more transparent and open.

\section{THE SCHOLARSHIP EVALUATION MECHANISM IN COLLEGES AND UNIVERSITIES}

The scholarship assessment basis generally includes academic performance and other additional sub-items. The calculation methods of each university will have different aspects depending on the actual situation. In general, academic performance may include professional courses, elective courses, public compulsory courses, and general school general courses, but different schools may use some or all of them in the scholarship evaluation. The additional scores mainly include ideological aspects, physical aspects, cadres, participation in various competitions inside and outside the school, scores of CET-4 and CET-6.

\section{A. Academic Achievement}

There are two calculation methods for general academic achievement: weighted average and arithmetic mean [3]. The weighted average score is defined as follows:

GPA(weighted average $)=\frac{\sum(\text { Course Credits }) \times(\text { Course Score })}{\sum(\text { Course Credits })}$

Among them, the total credits of students should receive the sum of credits for all courses in the previous school year. This method fully considers the influence of the importance of the course on the calculation results, and has a certain guiding effect on the student's learning time allocation.

The arithmetic averaging algorithm simply sums all course scores by the number of courses. This method considers all courses to be equally important and can promote the overall development of students to a certain extent.

\section{B. Additional Scores}

In terms of additional scores, according to statistics, there are some colleges and universities do not consider this item [4] and only consider the academic performance of students, they believe that academic performance can reflect students learning situation more objectively.

Although the systems for assessing scholarships in different universities are not the same, they are basically considered on the moral, intellectual, and intellectual aspects of students, and ensuring the fairness, openness, and impartiality of scholarship evaluation.

\section{The Automated Method of College Student SCHOLARSHIP ASSESSMENT}

Scholarships include national scholarships, national motivational scholarships, provincial scholarships, special scholarships offered by companies or alumni, and school scholarships. The first few scholarships generally have a large amount and a small number of places. They will be evaluated separately, while the school-level scholarships are not high, but the coverage ratio is the largest, and the evaluation procedure is the most complicated, which is the focus of the counselor's work.

Due to the complexity and diversity of the scholarship assessment methods, this method is limited to my school and only considers the school-level scholarship assessment. The implementation process is as follows:

First, according to the implementation method of the college-based junior college student scholarship in the "Student Handbook" of the school, including basic conditions, calculation methods of academic achievement, covered subjects, and the proportion of scholarship coverage at each level. The school's "Excellent Student Models", "Excellent Students", and "Excellent Student Cadres" appraisal methods include additional scores for each honor. We would comprehensive analysis the procedures and conditions in the scholarship assessment process.

Second, accurately analyze the grades of students in this year's grades and the conditions of bonus points, and form data tables according to the algorithm requirements, including the students' original scores, the CET-6 list, the outstanding students of the school, the outstanding student cadres or the excellent students, and the awards of each competition, singlequality award list, penalty list, etc.

Third, according to the scholarship evaluation procedure, an algorithm flow chart is formed, and the code is written according to the flow chart to implement the scholarship evaluation process. 
Fourth, the student data is input into the algorithm to generate a student's grade ranking, which provides a reliable basis for the scholarship assessment. And it can be used for a long time by transforming the data, reducing manual labor for future work and improving the efficiency of the work.

The detailed flow chart of the algorithm is defined as Fig. 1.

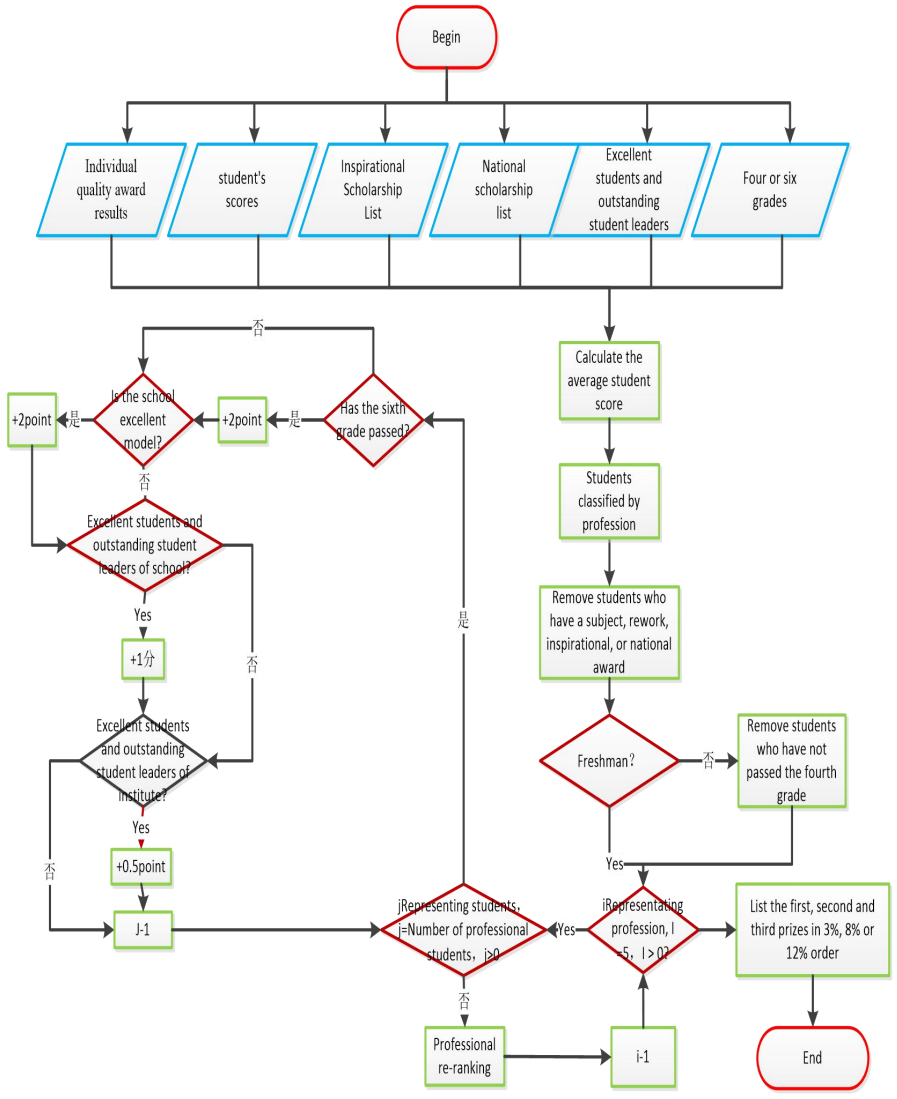

Fig. 1. The Algorithm flowchart

It is easy to understand the evaluation method of the scholarship through the above flow chart. At present, the automated method is only including the scholarship automatic evaluation process, and it would free the hands of the counselor and improves the accuracy and efficiency of the scholarship assessment, but this system does not cooperate with the academic affairs, the student work management system and other systems related to student information, and are still in the primary development stage, it will continue to be improved in the later stage.

\section{THE IMPLEMENTATION}

We did a lot of experiments to verify the accuracy of the algorithm, and the experimental data comes from the most of the students in our college, whose performance data comes from the educational management system, and the winning information comes from the student work management system. The data we used includes the individual quality award, students' scores, inspirational scholarship, national scholarship, excellent students and outstanding student leaders list, CET-4 or CET-6 score and awards for various competitions. In our school, the scholarship assessment methods for freshman and senior grades are different, and the scholarship is assessed according to the major rather than the entire grade, the number of different majors is different unless the number of student is equal.

The result of students' scores were added to additional scores is showing in Fig. 2.

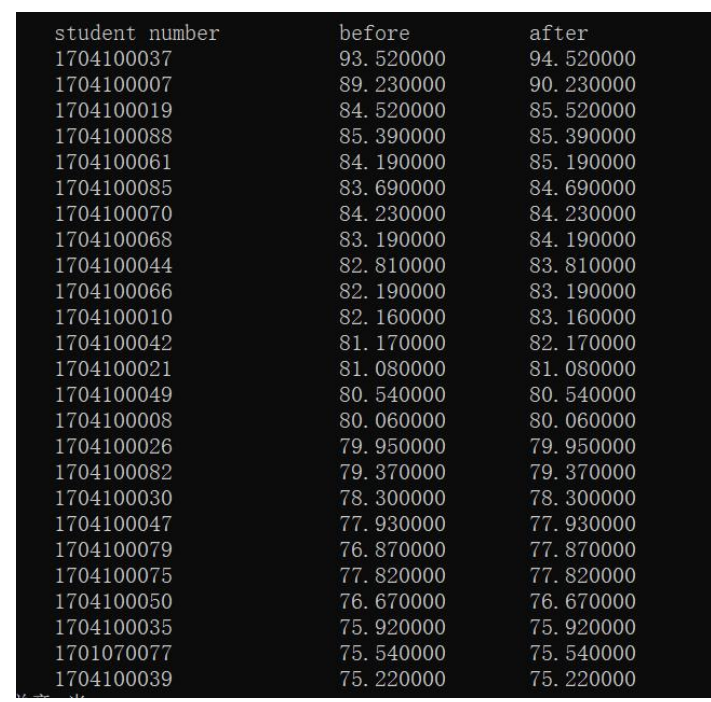

(a) Student's achievement ranking

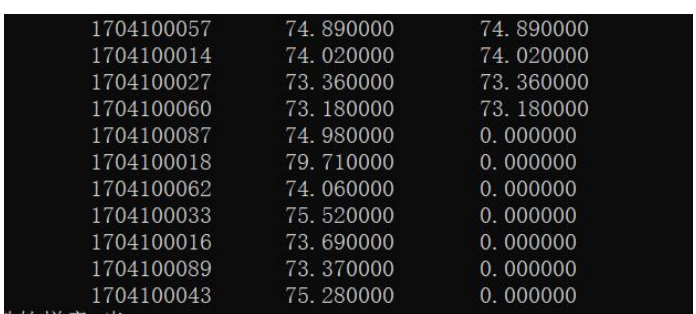

(b) 0.0 means no scholarship qualification

Fig. 2. The result of students' scores were added to additional scores

The above picture shows the student number of a major, the student's raw score and the student's comprehensive score. And the comprehensive score is the basis of the scholarship level. Among them the score is equal to zero means that the student does not qualify for the scholarship.

The scholarship result is showing in Fig. 3.

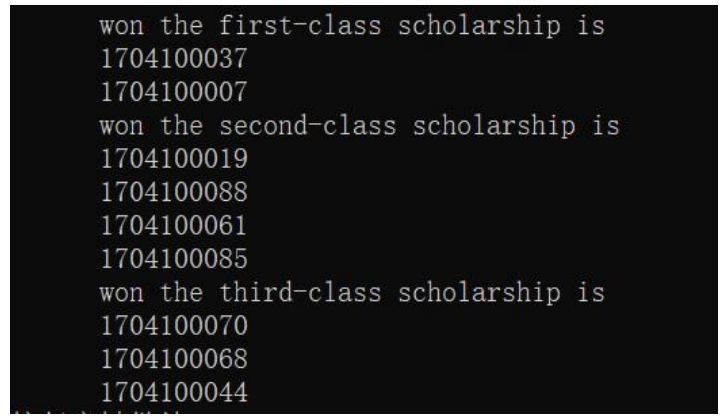

Fig. 3. The scholarship result 
The above scholarship evaluation method realizes the automation of the process through computer programming technology, and the qualification conditions of the scholarship are clearly classified. After the data such as the student's grade and the award information are entered, the algorithm automatically excludes the students who do not meet the requirements according to the grades. The students are ranked by grade, and the list of scholarship students and the scholarship level are output as a percentage. It may free the counselor from the complicated and complicated manual document work; we only need to provide the student's transcript, four or six grades, and the list of award-winning students according to the algorithm requirements. The algorithm directly outputs the first, second and third grade scholarship list. The results are clear, accurate, fast and reproducible.

\section{SUMMARY}

At present, the student achievement inquiry system of the school is separate from the student evaluation system. The scholarship assessment is based on student achievement, so in order to fully automate the scholarship assessment system, each department needs to coordinate and work together. This is a long-term, continuous update and improvement process. The interface of this scholarship evaluation system has not been designed, and will be further improved in the later stage, and strive to make a brief, practical and beautiful management system.

\section{REFERENCES}

[1] Tiantian Lian, "Study on Informatization of university scholarship management project - Taking Quanzhou Normal University as an example[D]," HUAQIAO UNIVERSITY, 2014.(In Chinese)

[2] Yuping Liao, "Research on the Status Quo and Innovation Measures of University Scholarship Work," Journal of Tian zhong, voL.30 No.1 Feb.2015. (In Chinese)

[3] Meng Ren, "Investigation, Research and Analysis of University Scholarship Evaluation System," ACADEMY, 2012.4. (In Chinese)

[4] Haimei Pan, "On the research and implementation of students scholarship evaluation system in vocational college[D]," ZHONHSHAN NUIVERSITY, 2014.(In Chinese)

[5] Xiaochun Gu, "Design and Research of Scholarship Assessment System of University," Master Thesis, 2008. (In Chinese)

[6] Jiangling Yu, "Research and Analysis on the Scholarship Management System of Jiangxi Fashion Institute[D]," YUNNAN UNIVERSITY, 2016. (In Chinese)

[7] Shijian Li, "Talking about the Problems and Incentive Mechanism of University Scholarships," Course Education Research, 2013.7. (In Chinese) 